\title{
New Civic Responsibilities for Online Service Providers
}

\author{
Mariarosaria Taddeo ${ }^{1,2}$, Luciano Floridi ${ }^{1,2}$ \\ ${ }^{1}$ Oxford Internet Institute, University of Oxford, UK \\ ${ }^{2}$ Alan Turing Institute, London, UK \\ mariarosaria.taddeo@oii.ox.ac.uk
}

Online Service Providers (OSPs)—such as AOL, Facebook, Google, Microsoft, and Twitter-are increasingly expected to act as good citizens, by aligning their goals with the needs of societies, supporting the rights of their users (Madelin 2011; Taddeo and Floridi 2015), and performing their tasks according to "principles of efficiency, justice, fairness, and respect of current social and cultural values" (McQuail 1992, 47). These expectations raise questions as to what kind of responsibilities OSPs should bear, and which ethical principles should guide their actions.

Addressing these questions is a crucial step to understand and shape the role of OSPs in mature information societies (Floridi 2016). Without a clear understanding of their responsibilities, we risk ascribing to OSPs a role that is either too powerful or too little independent. The FBI vs. Apple case, ${ }^{1}$ Google's and Yahoo!'s experiences in China, ${ }^{2}$ or the involvement of OSPs within the NSA's PRISM program ${ }^{3}$ offer good examples of the case in point. However, defining OSPs' responsibilities is challenging. Three aspects are particularly problematic: disentangling the implications of OSPs' gatekeeping role in information societies; defining fundamental principles to guide OSPs' conduct; and contextualising OSPs' role within the broader changes brought about by the information revolution.

The notion of 'gatekeepers' identifies those agents who have a central role in the management of resources and infrastructures that are crucial for societies (Lewin 1947). In our societies, OSPs are information gatekeepers (Calhoun 2002), as they control access to and flows of data and information (Shapiro 2000; Hinman 2005; Laidlaw 2008). As

\footnotetext{
${ }^{1}$ https://en.wikipedia.org/wiki/FBI-Apple_encryption_dispute

2 http://business.time.com/2014/01/08/are-google-yahoo-and-microsoft-living-up-to-their-promises-inchina/

${ }^{3}$ https://www.reformgovernmentsurveillance.com
} 
such, they exercise a regulatory function (Metoyer-Duran 1993), which entails moral responsibilities toward the public good. As Shapiro put it

those who control the access to information have a responsibility to support the public interest. [...] and must assume an obligation as trustees of the greater good (Shapiro 2000, 225).

While there is a general consensus on OSPs' gatekeeping role and on their ability to influence the development of information societies, there is much less agreement on whether, as corporate agents, OSPs bear any responsibility toward the public good (Freeman 1999; Black 2001; Taddeo and Floridi 2015). As a result, the civic responsibilities of OSPs are often discharged via policies and practices unilaterally defined by OSPs themselves.

Things become more complicated once we consider the international and inevitably multicultural contexts in which OSPs operate, the transnational nature of their business, alongside the interdependency of the services that they offer in different regions of the world. In this context, the definition of the responsibilities of OSPs will be effective only insofar as it will rest on an ethical framework able to reconcile the different views and stakeholders' interests that they face.

Human rights have a central role in this debate, insofar as they identify fundamental universal principles, some of which expressly address Internet governance (Wettstein 2012b; Lucchi 2013). For example, a report ${ }^{4}$ released by the UN in 2011stressed that

[g]iven the Internet has become an indispensable tool for realizing a range of human rights, combating inequality, and accelerating development and human progress, ensuring universal access to the Internet should be a priority for all States.

In 2012, Internet freedom was declared a human right by the UN Human Rights Council, which called on states to promote and foster access to the Internet and to ensure that the rights to freedom of expression and information, as presented in Article 19 of the Universal Declaration of Human Rights, would be upheld online as well as offline. ${ }^{5}$ However, both the Universal Declaration of Human Rights and the Resolution on the Promotion, Protection and Enjoyment of Human Rights on the Internet ${ }^{12}$ mainly

\footnotetext{
${ }^{4}$ http://www2.ohchr.org/english/bodies/hrcouncil/docs/17session/A.HRC.17.27_en.pdf

${ }^{5}$ Resolution on "The Promotion, Protection and Enjoyment of Human Rights on the Internet" (Human Rights Council of the United Nations 2012).
} 
address state actors, making problematic the expectation that OSPs should be held responsible for respecting and fostering human rights (Karp 2009). This problem is not entirely new. The scope of human rights and the responsibilities that they pose to transnational corporations have already been analysed in the Declaration of Human Duties and Responsibilities (the so-called Valencia Declaration). The Declaration stresses the moral duties and legal responsibilities of all the members of the global community to observe and promote respect for human rights and fundamental freedoms. The global community encompasses state and non-state actors, individuals and groups of citizens, as well as the private and the public sector. Private companies are also expressly mentioned as responsible for promoting and securing human rights in the preamble of the UN Norms on the Responsibilities of Transnational Corporations and Other Business Enterprises.

Given OSPs' central role in shaping the informational environment and the societies depending on it, it is increasingly less acceptable to maintain that, as private companies, OSPs are only responsible to their employees and shareholders, and are not bounded by human rights regulation (Chen 2009; Taddeo and Floridi 2015; Cath and Floridi 2016; Laidlaw Forthcoming). This is a point highlighted, for example, in the latest report of the Special Rapporteur on freedom of expression to the Human Rights Council, David Kaye, who stressed that

Among the most important steps that private actors should take is the development and implementation of transparent human rights assessment procedures. They should develop and implement policies that take into account their potential impact on human rights. ${ }^{6}$

At the same time, however, it is problematic to ascribe to OSPs full responsibility for fostering and respecting human rights, and for deciding the circumstances in which these apply. For this prompts a privatization of the judging power and poses issues of transparency and accountability (Gerry and Berova 2014). Consider, for example, OSPs acting as both the "judge and the jury"7 with respect to the decision of the European Court of Justice on the right to be forgotten (Rosen 2012; Floridi 2015). To this end, it is crucial to separate the responsibilities of OSPs from the duties and authority of the state.

\footnotetext{
${ }^{6}$ http://www.ohchr.org/EN/Issues/FreedomOpinion/Pages/Privatesectorinthedigitalage.aspx ${ }^{7}$ http://www.telegraph.co.uk/technology/google/10967211/Google-is-the-judge-and-jury-in-the-right- tobe-forgotten.html.
} 
Guidance on this matter has been provided by the Ruggie's framework. ${ }^{8}$ The framework proposes a clear-cut distinction between the role of states and that of transnational corporations with respect to human rights (Wettstein 2012a). The distinction rests on three pillars: the duty of the state to protect against human rights abuses by third parties, including business; the corporate responsibility to respect human rights; and the responsibility of both states and corporates to provide victims with access to effective remedy, both judicial and non-judicial.

While the Ruggie's framework offers a valid tool to identify the responsibilities of transnational corporations, the proposed distinction between states' duties and corporates' responsibilities proves to be problematic when considering specifically the case of OSPs. Their crucial role in information societies, alongside their leading role in steering the information revolution and, hence, in shaping the informational environment make them political agents able to influence national politics and international relations (Broeders and Taylor forthcoming). As such, they differ quite radically from other transnational corporations and bear a wider set of responsibilities than other corporate agents (Scherer and Palazzo 2011). Broders and Taylor argue that, as political agents, OSPs should bear corporate political responsibilities:

OSPs exercise power over their users and are a counter power to state power in all corners of the world. [...] they are also political actors who merit serious diplomatic attention owing to their vital role in digital life, [...] (Broeders and Taylor forthcoming).

The Ruggie's framework only partially addresses OSPs' political role and offers little insight to identify states' duties in cyberspace. Insofar as the framework rests on the Westphalian model of sovereign states, it struggles to address new forms of political agents - like the EU and the UN-or NGOs (Nye 2004). At the same time, the model is challenged when considering sovereign states' authority in cyberspace, where it is problematic to draw national boundaries, and state's territoriality and sovereignty are difficult to define (Krasner 2001).

The limitations of the Ruggie's framework point to the third set of problems concerning the definition of OSPs' civic responsibilities, namely the understanding of the conceptual and moral changes (Floridi 2014; Taddeo and Buchanan 2015) brought about by new phenomena such as, for example, Big Data analytics (Floridi 2012; Mittelstadt and Floridi

${ }^{8}$ http:/ / 198.170.85.29/Ruggie-protect-respect-remedy-framework.pdf 
2015), individual and group privacy (Floridi 2014), online trust (Taddeo 2010; Taddeo and Floridi 2011), cyber security and surveillance (Taddeo 2013; Taddeo 2014b), and cyber conflicts (Taddeo 2012; Taddeo 2014a; Floridi and Taddeo 2014). These changes concern the redefinition of crucial concepts, like those of political power and authority, as well as the distinction between real and virtual and the understanding of good and evil, and of the values on which present and future information societies rely.

The civic responsibilities of OSPs cannot be defined without considering these conceptual changes and without a foresight analysis of the future of information societies, toward which OSPs play a decisive role. In (Taddeo and Floridi 2015), we argued that the notion of information gatekeepers, the human rights framework, and the concepts of respect and care for the informational environment (Floridi 2013a) offer key milestones for an ethical framework able to identify and define both the civic responsibilities of OSPs and the right ethical infrastructure, i.e. the infraethics (Floridi 2013b), able to facilitate the discharging of such responsibilities. This requires identifying those

"expectations, attitudes, and practices that can facilitate and promote morally good decision and actions" (Floridi 2013b, 738).

In the case of OSPs, the right infraethics encompasses trust, privacy, and transparency, as well as openness and pluralism.

It is clear that the definition of OSPs' responsibilities and of the infraethics supporting them will increasing shape the informational environment and future information societies (Floridi 2011; Cath and Floridi 2016). For this reason ad hoc approaches, tackling OSPs' responsibilities as they emerge, will be insufficient in the medium- and long-term, for they lack a meaningful reflection on current changes and any insight on future ones. Both can only be achieved by coordinating expertise and theorising to understand the values that will continue shaping our societies, the different stakeholders' views, alongside the role of OSPs and of other key agents in designing the informational environment.

This volume provides a step in this direction, by collecting eighteen contributions addressing the issue of OSPs' responsibilities from different angles. Each contribution is either invited or a paper presented during the workshop "Understanding the Responsibilities of Online Service Providers in Information Societies", held in 2015 at the Oxford Internet Institute, University of Oxford. The goal is to offer a multidisciplinary collection of essays 
spanning from ethics and corporate social responsibilities to policy and legal analyses of OSPs civic responsibilities. The volume is divided into three parts, focusing on 'Responsibilities \& Liabilities', 'Business Ethics \& Policies', and 'Users' Rights \& International Regulations' respectively.

Chapter one-The debate on the moral responsibilities of online service providers-opens the first part of the book, with a reprinted version of a paper appeared in 2015 (Taddeo and Floridi 2015). It analyses the main contributions to the debate on the moral responsibilities of OSPs. By endorsing the method of the levels of abstraction (LoAs) (Floridi 2008), it first focuses on the moral responsibilities of OSPs in the web (LoA $\left.A_{\mathrm{IN}}\right)$. These concern the management of online information, which includes information filtering, Internet censorship, the circulation of harmful content, and the implementation and fostering of human rights. The chapter then delves into the moral responsibilities ascribed to OSPs on the web $\left(\mathrm{LoA}_{\mathrm{ON}}\right)$ describing existing legal regulations of access to users' data. The analysis highlights two main results. First, OSPs' public role-especially their gatekeeping function, their corporate social responsibilities, and their role in implementing and fostering human rights-has acquired increasing relevance in the specialised literature. Second, there is a lack of an ethical framework that can (a) define OSPs' responsibilities, and (b) provide the fundamental sharable principles necessary to guide OSPs' conduct within the multicultural and international context in which they operate.

The analysis of OSPs responsibilities in the web continues in the second chapter-The immunity of internet intermediaries reconsidered? - which focuses on the role of OSPs in the digital world. The goals of this contribution are to identify the role of new power players in the digital world and to analyse the boundaries between immunity and liability of Internet intermediaries. Specifically, this contribution addresses questions such as: will OSPs become quasi judges controlling every Internet activity? Are they entitled to defend the rights of the users and, more in general, the legitimacy in cyberspace? Which principles and policies should be adopted in order to foster an ethos of compliance and social responsibility for these new gatekeepers?

Chapter three-Is Google responsible for providing fair and unbiased results?-focuses on the responsibility of search engines in general, and Google in particular, for providing unbiased search results. The chapter identifies areas of potential responsibilities of search engines by endorsing two approaches, one technical and the other societal. The technical 
approach considers the impact of decisions made at the design stage on users' search results. The societal approach informs discussion on the impact that biased search engines may have for information and knowledge acquisition in society.

Chapter four-Speaking truth to/as victims, a jurisprudential analysis of data breach notification laws - analyses the duty that OSPs have to inform customers when the company suspects security breaches and unauthorised access to customer data. This chapter focuses on data breach notification duties from a jurisprudential perspective and considers what duties can legitimately be attributed to victims of crime in a democratic society. It then applies this analysis to OSPs and their duty to inform either their customers or a state agency about data breaches.

Chapter five-Did the Romans get it right? What Delfi, Google, eBay, and UPC TeleKabel Wien bave in common - concludes the first part of the volume by providing a description of the legal principles set out in recent landmark cases of both the EU Court of Justice in Luxembourg (CJEU) and the European Court of Human Rights (ECHR), including the Google France, Google Spain/Costeja, UPC TeleKabel Wien and Delfi cases. It examines the legal grounds and arguments put forward by the respective courts in order to judge OSPs' responsibilities.

The second part of the book collects analyses focusing on business ethics and corporate social responsibilities. Chapter six-Responsibilities of OSPs from a business ethics point of view-opens this part by focusing on a central aspect of the business ethics debate, i.e. the balance between OSPs' responsibilities and their ability to be competitive in the market. This chapter argues, first, that the analysis of OSPs' business responsibilities should rest less on purely individual concepts of responsibility and more on the concepts of group agency; and, second, that there are ways of ascribing responsibility to companies compatible with competition, as the debate on corporate social responsibilities (CSR) shows.

The analysis on OSPs' CSR continues in chapter seven-Myth or promise? The corporate social responsibilities of online service providers for buman rights. The chapter analyses a number of CSR frameworks shaping OSPs' conduct. In particular, it concentrates on the UN Guiding Principles and on the Global Network Initiative, one of the leading multistakeholder initiatives guiding CSR for technology companies. The goal is to address OSPs' accountability with respect to human rights. In doing so, the chapter focuses on key issues such the relevance of CSR frameworks for protecting human rights online. 
Chapter eight-Online Service Providers — a new and unique species of the firm? - draws on crossdisciplinary literature from economic theory, international business theory, economic geography, and information technology, in order to analyse whether OSPs differ from other transnational corporations and whether this entails different CSRs. The chapter concludes that, albeit OSPs differ from other transnational corporations, such difference are not wide enough to consider OSPs a unique kind of firm. The analysis then focuses on the non-monetary relationship between OSPs and their end-users, and on the societal impact that this could have, especially in developing countries.

Chapter nine-Online service providers as human rights arbiters — continues the analysis of fair policies for OSPs and of their responsibilities with respect to human rights. The chapter focuses on case-studies of EU regulation such as the E-commerce directive, to assess whether and to what extent measures of blocking, filtering, and content removal interfere with the human rights standards related to freedom of expression and freedom of information. The chapter concludes that OSPs' self-defined guidelines are insufficient to counter the human rights challenges.

Chapter ten-Licensing of user-generated content: why less is more-delves into the responsibilities of OSPs with respect to users-generated content that is subject to licensing clauses found in terms of service agreements. The chapter argues that contractual ambiguity existing in OSPs' terms of service agreements negatively affects users and OSPs alike.

The third part of the book is dedicated to 'Users' rights \& international regulations' and begins with chapter eleven-Online service providers' liability, copyright infringement, and freedom of expression. Could Europe learn from Canada? This contribution analyses recent interpretations of the Dir. 2000/31, which have lifted the bar on providers' duties and highlights their impact on OSPs business and, most important, on freedom of expression. The chapter then focuses on the Canadian regulation, which is based on the so-called 'notice and action' principle, and suggests it offers a suitable framework for the regulation of OSPs' liabilities in Europe.

Chapter twelve-Non-financial disclosures in the tech sector: furthering the trend-focuses on transparency and analyses the different ways through which corporate non-financial disclosure mechanisms can contribute to developing an ethical framework for OSPs. The chapter discusses three areas where transparency makes an impact on ethical standards for OSPs: corporate reporting on interaction with governments on privacy and free 
expression issues; disclosures of staff demographics; and sharing of information on digital security topics, including encryption and breach. Finally, it assesses the ways through which transparency mechanisms, and their consistent implementation, could help OSPs realize their new civic responsibilities.

Chapter thirteen-Should we treat Big Data as a public good?-discusses Big Data and the responsibilities of OSPs to ensure that the user-generated data continue to improve individual well-being, innovation, and sustainable development. To this end the chapter maintains that Big Data should be considered a public good and that platforms for public and private partnerships in managing Big Data should be in place.

Chapter fourteen-Internet intermediaries as responsible actors? Why it is time to rethink the eCommerce Directive as well-questions the suitability of the e-Commerce Directive. The purpose of this chapter is twofold. It aims to show that there is a need to review Articles 12 to 15 of the e-Commerce Directive; and that the very rationale linking Articles 12 to 14 of the e-Commerce Directive is ill-suited to address the complexity and diversity of OSPs' activities.

Chapter fifteen-Towards fostering compliance by design, drawing designers into the regulatory frame-begins by considering the extent to which EU General Data Protection Regulations would redefine the governance of personal data in a series of key ways and focuses, in particular, on the 'by design and by data protection'. It argues that this notion shifts the responsibility away from the user and explicitly invokes the role of the designer within the regulatory frame. The chapter then describes ideation cards as a suitable method to foster cross-disciplinary collaborations. It maintains that, whilst such cards will not necessarily create experts in data protection, they have the potential to sensitise designers to existing regulation.

Three commentaries conclude the volume. The first one-Does great power come with great responsibility? The need to talk about Corporate Political Responsibility-analyses the role of OSPs in contemporary societies and argues that OSPs act as political agents, with a relevant role in both national politics and international relations. Such a role requires extending the scope of the CSR that OSPs bear in two ways:

[...] more serious mechanisms for accountability and (b) a recognition of the political role of corporations (Broeders and Taylor forthcoming). 
The second commentary-The Economic Impact of Online Intermediaries - focuses on the role of Internet intermediaries to drive economic, social, and political development and considers whether the consolidation of OSPs' economic power impacted conventional business trade models and changed firm-level competition. It concludes that, while OSPs have provided technologically superior market entrants, they have not yet disrupted supply-chains, with the exception of software, publishing, and professional services sectors, in which online intermediaries have provided tangible productivity gains.

The third commentary- Online Service Providers and ethical disclosure in sales—addresses the need to develop business norms for the commodification of user information by OSPs. This contribution maintains that in considering the responsibilities of OSPs, referring to business norms, rather than interpersonal moral norms, leads to draw ethical conclusions with clear normative force.

\section{References}

Black, Julia. 2001. "Decentring Regulation: Understanding the Role of Regulation and Self Regulation in a 'Post-Regulatory' World.” Current Legal Problems 54 (1): 10346.

Broeders, Dennis, and Linnet Taylor. Forthcoming. "Does Great Power Come with Great Responsibility? The Need to Talk about Corporate Political Responsibility." In , edited by Mariarosaria Taddeo and Luciano Floridi. Law, Governance and Technology Series. Springer Berlin Heidelberg New York London.

Calhoun, Craig J., ed. 2002. Dictionary of the Social Sciences. New York: Oxford University Press.

Cath Corinne, and Luciano Florid. 2016. "The Design of the Internet's Architecture by the Internet Engineering Task Force (IETF) and Human Rights." Science and Engineering Ethics, May.

Chen, Stephen. 2009. "Corporate Responsibilities in Internet-Enabled Social Networks." Journal of Business Ethics 90 (4): 523-36.

Floridi, Luciano. 2014. The Fourth Revolution, How the Infosphere Is Reshaping Human Reality. Oxford: Oxford University Press. 
Floridi, Luciano. 2008. "The Method of Levels of Abstraction.” Minds and Machines 18 (3): 303-29.

Floridi, Luciano. 2011. "A defence of constructionism: Philosophy as conceptual engineering." Metaphilosophy 42 (3): 282-304

Floridi, Luciano.2012. "Big Data and Their Epistemological Challenge.” Philosophy \& Technology 25 (4): 435-37.

Floridi, Luciano.2013a. The Ethics of Information. Oxford: Oxford University Press.

Floridi, Luciano.2013b. "Distributed morality in an information society." Science and engineering ethics 19 (3):727-743

Floridi, Luciano.2014. “Open Data, Data Protection, and Group Privacy.” Philosophy \& Technology 27 (1): 1-3.

Floridi, Luciano.2015. "Should You Have The Right To Be Forgotten On Google? Nationally, Yes. Globally, No.” New Perspectives Quarterly 32 (2): 24-29.

Floridi, Luciano.2016. "Mature Information Societies-a Matter of Expectations." Philosophy \& Technology 29 (1): 1-4.

Floridi, Luciano., and Mariarosaria Taddeo, eds. 2014. The Ethics of Information Warfare. New York: Springer.

Freeman, Jody. 1999. "Private Parties, Public Functions and the New Administrative Law.” SSRN Scholarly Paper ID 165988. Rochester, NY: Social Science Research Network.

Gerry, Felicity, and Nadya Berova. 2014. "The Rule of Law Online: Treating Data like the Sale of Goods: Lessons for the Internet from OECD and CISG and Sacking Google as the Regulator." Computer Law \&amp; Security Review 30 (5): 465-81.

Hinman, Lawrence. 2005. "Esse Est Indicato in Google: Ethical and Political Issues in Search Engines." International Review of Information Ethics 3 (6): 19-25.

Human Rights Council of the United Nations. 2012. "U.N. Human Rights Council: First Resolution on Internet Free Speech.” http://www.loc.gov/lawweb/servlet/lloc_news?disp3_1205403231_text. 
Karp, David Jason. 2009. “Transnational Corporations in 'bad States': Human Rights Duties, Legitimate Authority and the Rule of Law in International Political Theory." International Theory 1 (01): 87.

Krasner, Stephen D. 2001. "Rethinking the Sovereign State Model." Review of International Studies 27 (05).

Laidlaw, Emily. Forthcoming. "Myth or Promise? The Corporate Social Responsibilities of Online Service Providers for Human Rights." In The Responsibilities of Online Service Providers, edited by Mariarosaria Taddeo and Luciano Floridi. Law, Governance and Technology Series. Springer Berlin Heidelberg New York London.

Laidlaw, Emily. 2008. "Private Power, Public Interest: An Examination of Search Engine Accountability." International Journal of Law and Information Technology 17 (1): 11345.

Lewin, Kurt. 1947. "Frontiers in Group Dynamics.” Human Relations 1 (2): 143-53.

Lucchi, Nicola. 2013. "Internet Content Governance and Human Rights." Vanderbilt Journal of Entertainment and Technology Law 16: 809.

Madelin, Robert. 2011. "The Evolving Social Responsibilities of Internet Corporate Actors: Pointers Past and Present." Philosophy \& Technology 24 (4): 455-61.

McQuail, Denis. 1992. Media Performance: Mass Communication and the Public Interest. London ; Newbury Park, Calif: Sage Publications.

Metoyer-Duran, Cheryl. 1993. "Information Gatekeepers." Annual Review of Information Science and Technology (ARIST) 28: 111-50.

Mittelstadt, Brent Daniel, and Luciano Floridi. 2015. “The Ethics of Big Data: Current and Foreseeable Issues in Biomedical Contexts." Science and Engineering Ethics, May.

Nye, Joseph S. 2004. Soft Power: The Means to Success in World Politics. 1st ed. New York: Public Affairs.

Rosen, Jeffrey. 2012. “The Right to Be Forgotten.” Stanford Law Review Online 64: 88.

Scherer, Andreas Georg, and Guido Palazzo. 2011. “The New Political Role of Business in a Globalized World: A Review of a New Perspective on CSR and Its 
Implications for the Firm, Governance, and Democracy." Journal of Management Studies 48 (4): 899-931.

Shapiro, Andrew L. 2000. The Control Revolution: How the Internet Is Putting Individuals in Charge and Changing the World We Know. 2nd.Printing edition. New York: PublicAffairs.

Taddeo, Mariarosaria. 2010. "Modelling Trust in Artificial Agents, A First Step Toward the Analysis of E-Trust." Minds and Machines 20 (2): 243-57.

Taddeo, Mariarosaria. 2012. "Information Warfare: A Philosophical Perspective." Philosophy and Technology 25 (1): 105-20.

Taddeo, Mariarosaria. 2013. "Cyber Security and Individual Rights, Striking the Right Balance.” Philosophy \& Technology 26 (4): 353-56.

Taddeo, Mariarosaria. 2014a. “Just Information Warfare.” Topoi, April, 1-12.

Taddeo, Mariarosaria. 2014b. "The Struggle Between Liberties and Authorities in the Information Age." Science and Engineering Ethics, September, 1-14.

Taddeo, Mariarosaria, and Luciano Floridi. 2011. "The Case for E-Trust." Ethics and Information Technology 13 (1): 1-3.

Taddeo, Mariarosaria, and Elizabeth Buchanan. 2015. "Information Societies, Ethical Enquiries.” Philosophy \& Technology 28 (1): 5-10.

Taddeo, Mariarosaria, and Luciano Florid. 2015. "The Debate on the Moral Responsibilities of Online Service Providers." Science and Engineering Ethics.

Wettstein, Florian. 2012a. "CSR and the Debate on Business and Human Rights: Bridging the Great Divide.” Business Ethics Quarterly 22 (4): 739-70.

Wettstein, Florian. 2012b. "Silence as Complicity: Elements of a Corporate Duty to Speak Out Against the Violation of Human Rights.” Business Ethics Quarterly 22 (01): 37-61. 